\title{
Blowout fracture of the orbit
}

\section{Diagnosis and treatment}

\section{SIDNEY LERMAN}

From the Department of Ophthalmology, McGill University, Faculty of Medicine, Montreal, Quebec, Canada

One of the earliest descriptions of what is now referred to as blowout fracture of the orbit was reported by Lang ( 1889 ). The mechanism involved in this type of fracture was first suggested by Pfeiffer (1943) and later defined and proven by Converse (1962), Converse and Smith (1957, 1959, 1960), and Smith and Converse (1957).

A true blowout fracture of the orbit can occur as a specific syndrome without any other associated facial fractures (the so-called pure blowout fracture) or it can be found in association with multiple facial injuries as is frequently the case in automobile accidents. In general, the ophthalmologist is well equipped to diagnose and treat the pure blowout fracture, but the latter situation usually requires the services of a maxilliary-facial consultant to handle the associated facial injuries. This discussion will deal only with the pure blowout fracture of the orbit.

An examination of the bony orbit quickly reveals two areas of weakness; the orbital plate of the ethmoid bone which overlies the ethmoid sinuses and the orbital floor lying over the maxillary sinus (Fig. I). A blowout fracture usually occurs when a sudden blow to the eye pushes the intact globe back into the orbit. There is an associated momentary increase in intraorbital pressure resulting in a fracture or blowout through the thin portion of the orbital floor. The posterior displacement and sudden increase in intraorbital pressure can also result in a concomitant fracture of the medial wall of the orbit into the ethmoidal air sinuses. The orbital floor gives way in the manner of a safety valve with herniation of the periocular structures into and through the opening. In this way the globe itself is frequently spared from any serious injury although a small but significant number of patients has been reported in which intraocular pathology has accompanied a true blowout fracture. The mechanism involved in the development of a blowout fracture generally precludes small objects as aetiological factors. That is, a golf ball striking the globe would usually result in a rupture of the globe rather than a blowout fracture, but a larger object, such as a fist, a knee, a dashboard, etc., will result in a blowout fracture. Converse, Smith, Obear, and Wood-Smith (1967), listed the automobile, the human fist, and the human elbow as the most common aetiological factors in a series of 100 cases.

\section{Diagnosis}

Early diagnosis and treatment of a blowout fracture is extremely important since the prognosis in such cases is excellent. These fractures should generally be repaired within 5 to 7 days after injury. Late repair of such a condition is frequently difficult because of 


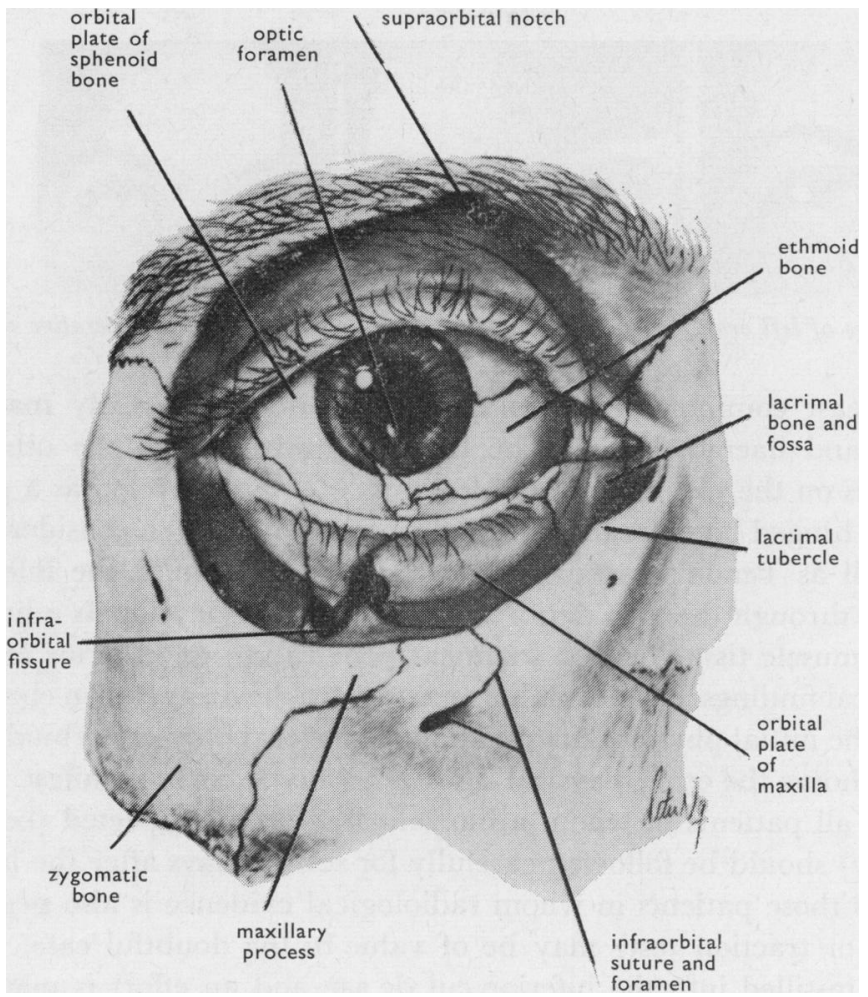

FIG. I Schematic representation of bony orbit and orbital contents

the associated scar tissue formation and the results are generally not as satisfactory. The most common physical findings observed in patients with pure blowout fractures include (in order of frequency):

(I) Periorbital ecchymosis (Fig. 2)

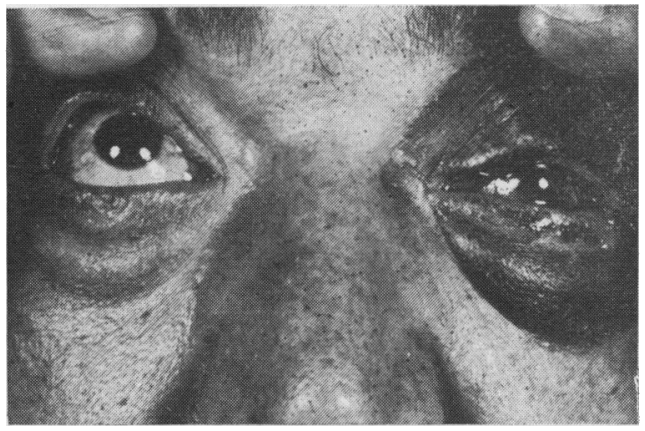

FIG. 2 Blowout fracture of left orbit, showing oedema, ecchymosis, and inability to elevate the globe

(2) Inability to elevate the globe (Figs 2 and $3 \mathrm{~A}$, overleaf)

(3) Vertical diplopia, hypotropia, or hypertropia on the affected side, depending on the location of the fracture (Figs 4 and 5, overleaf)

(4) Hypoaesthesia over the distribution of the infraorbital nerve

(5) Depression of the globe

(6) Enophthalmos. 


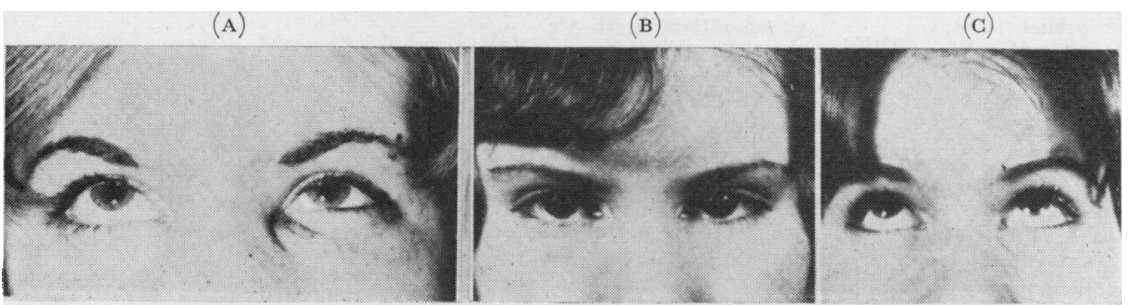

FIG. 3 Blowout fracture of left orbit, showing inability to elevate globe (A) and postoperative result (B and $\mathrm{C}$ )

The last is the least common presenting sign, because it is usually masked by the associated oedema and haemorrhage. The frequency with which the other signs are encountered depends on the size and type of fracture. It may develop as a punched-out piece of bone or as a hinged bony fragment of sufficient size to allow a considerable amount of orbital fat as well as Tenon's capsule, the inferior rectus and/or the inferior oblique muscles, to herniate through the torn periorbita. It may also develop as a linear fracture incarcerating some muscle tissue or as a fragment penetrating the inferior rectus muscle.

The typical physical findings usually enable one to make the diagnosis on clinical grounds (Figs 2 and 3A). The initial physical examination may reveal only periorbital ecchymosis, but within 24 to 48 hours the other physical signs generally become manifest. It is therefore important that all patients in whom a blowout fracture is suspected (because of the mechanism of injury) should be followed carefully for several days after the initial injury. This applies even to those patients in whom radiological evidence is also negative. The "entrapment test" (or traction test) may be of value in the doubtful case. In this test local anaesthesia is instilled into the inferior cul de sac and an effort is made to elevate the globe with forceps placed over the inferior rectus muscle.

The extraocular muscle imbalance is due to the entrapment of either the inferior rectus or the inferior oblique muscle or both. It is possible to predict the site of the fracture in relation to the equator of the globe. If the inferior rectus muscle is tethered anteriorly, the eye will be fixed in a depressed position, resulting in a hypotropia on the side of the injury when the opposite eye is in the primary position (Fig. 4). This imbalance will be

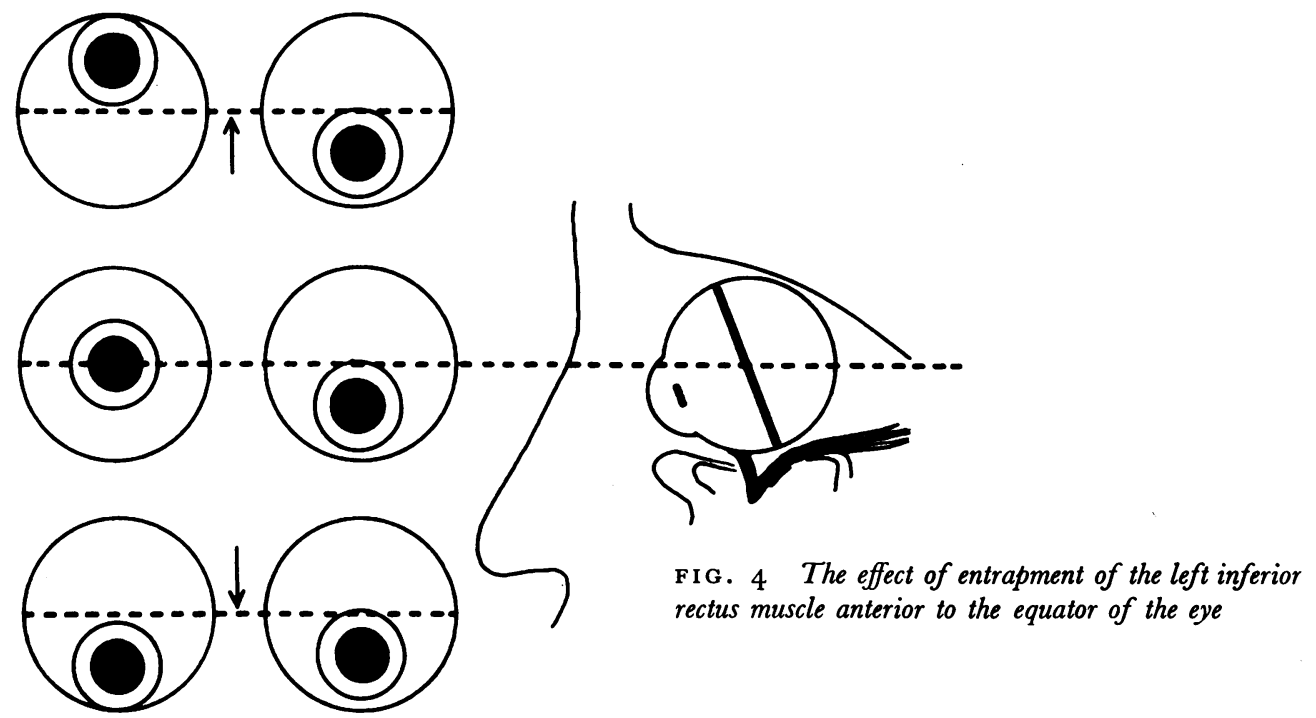


less marked on looking down and will be exaggerated on looking up. If the inferior rectus muscle is trapped posterior to the equator of the globe the eye will be fixed in an elevated position and in the primary position of gaze a hypertropia on the same side as the injury will result (Fig. 5). Hence, the imbalance will appear to be less on looking up and will be exaggerated on looking down. If the eyes appear to be straight in the primary position, this usually signifies a fracture located at the equator, and a vertical imbalance can then be demonstrated when the patient looks up or down (Fig. 6). It is, however, important to remember that retrobulbar haemorrhage can result in other nonspecific and variable signs of extraocular muscle imbalance, but these do not usually conform with the above pattern.
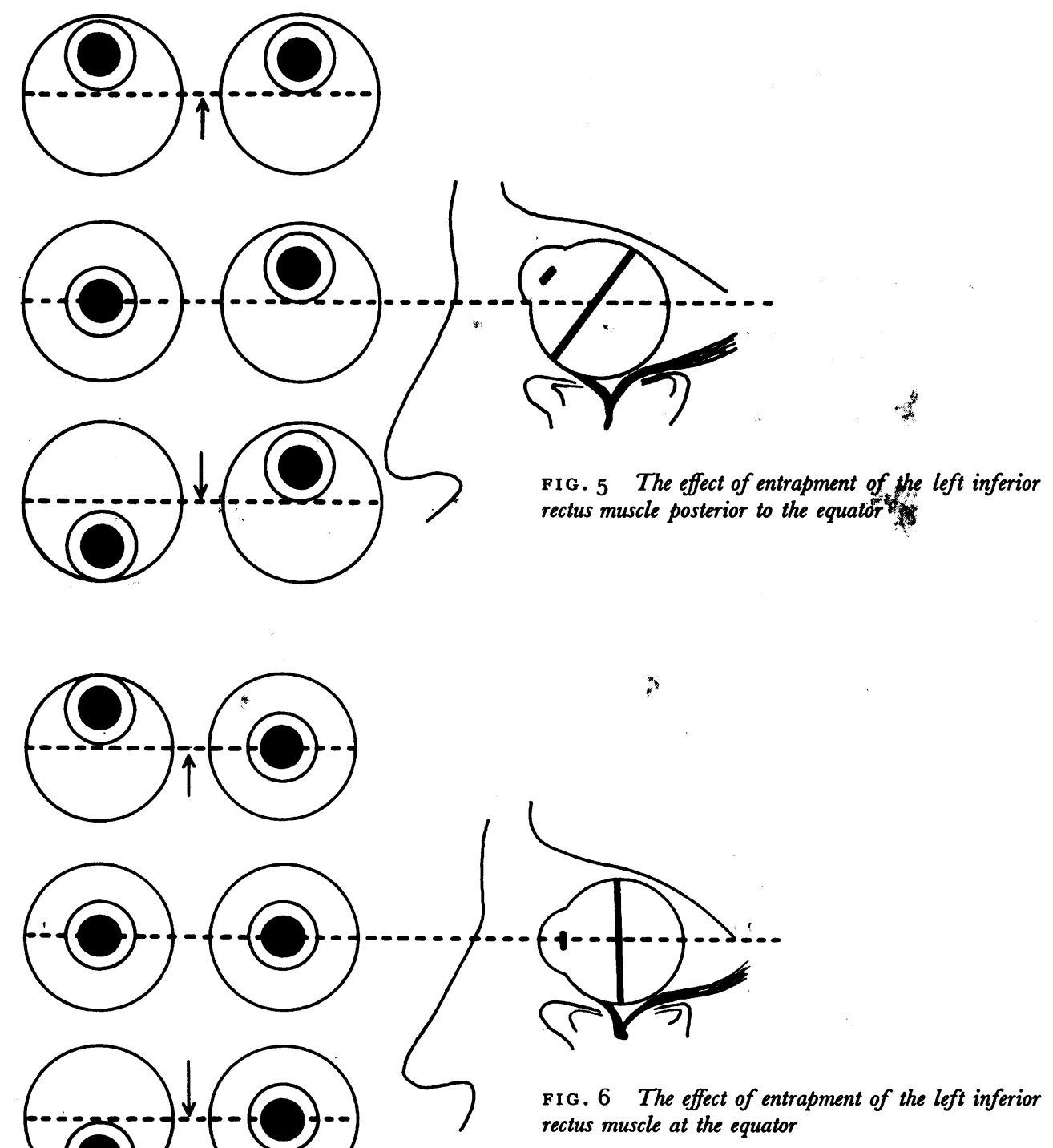
Between 20 and 35 per cent. of patients may show orbital emphysema which can be due to an associated fracture of the medial orbital wall involving the ethmoid air cells, or the blowout fracture into the maxillary antrum.

Serious ocular involvement associated with blowout fractures of the orbit, while not too frequent (because of the safety valve mechanism involved in the pathogenesis of this fracture), can occur; this may include hyphaema, traumatic iridodialysis, contusion cataract, subluxation of the lens, vitreous haemorrhage, commotio retinae, preretinal haemorrhages, retinal dialysis, and even giant tears in eyes with advanced degenerative retinal changes, and (rarely) traumatic amaurosis with optic atrophy. Secondary glaucoma following subluxation of the lens and angle recession glaucoma have also been reported (Aiello and Myers, I965; Milauskas and Fueger, 1966). A careful ocular examination is therefore an essential part of the evaluation of any patient with a blowout fracture.

Radiological examination should also be carried out in all patients suspected of having a blowout fracture. These include a slightly modified Waters projection and tomograms (Figs 7 and 8). Stereograms may also prove useful. The radiological findings in a blowout fracture include the following:

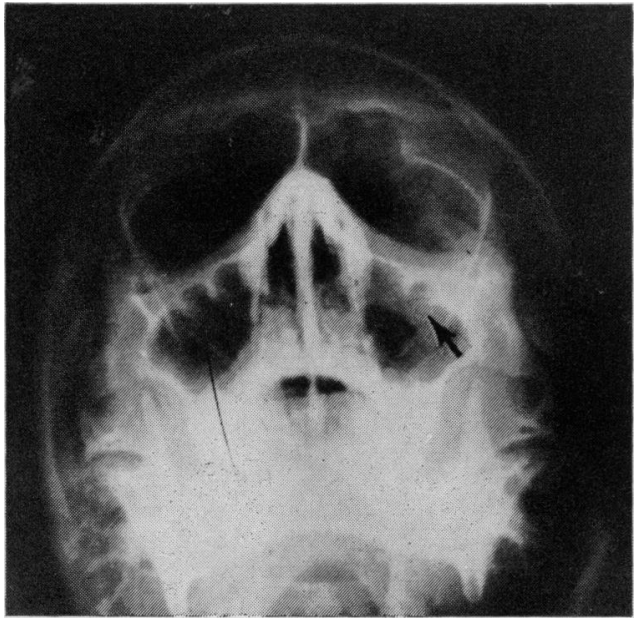

FIG. 7 Normal Waters x-ray projection. Arrow points to common site of "hanging-drop" opacity in a blowout fracture (see Fig. 9)

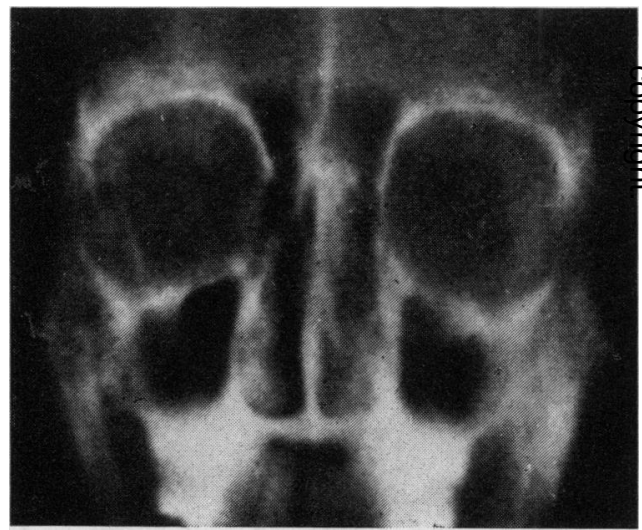

FIG. 8 Orbital tomogram, showing hanging-drop density in left orbit

(I) Periorbital oedema, as evidenced by a more radiopaque orbit and thickening of the soft tissue shadow over the inferior orbital rim.

(2) Orbital emphysema, particularly when there is an associated fracture involving the ethmoidal sinuses.

(3) Partial to complete opacification of the maxillary antrum. The opacification is usually due to associated haemorrhage (Fig. 9, opposite).

(4) The so-called hanging-drop opacity into the maxillary antrum (Fig. 9) due to herniation of the orbital contents through the fractured floor.

(5) Fragmentation and irregularity of the orbital floor. In some cases a fragment of bone depressed into the maxillary sinus may appear as a linear density in the soft tissue (hanging-drop) deformity. 


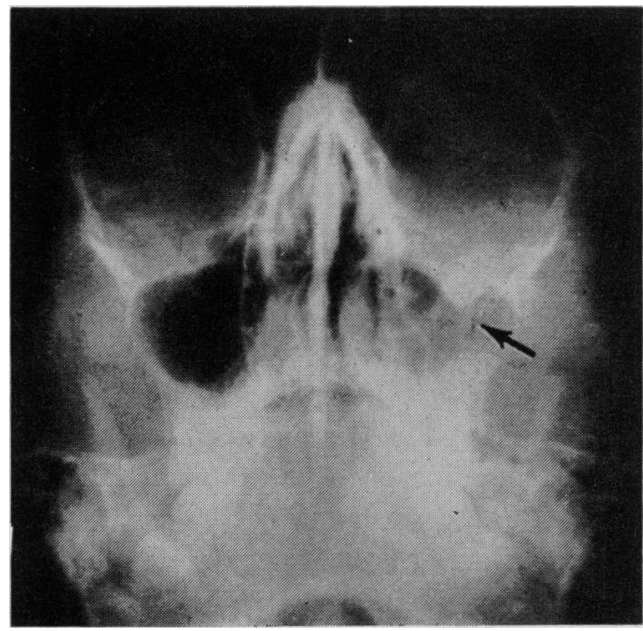

FIG. 9 Waters projection, showing "hangingdrop" opacity (arrow) in a patient with a blowout fracture of the left orbit

While radiological examination should be performed in all cases it should be noted that an occasional patient may fail to show any $x$-ray evidence of a blowout fracture of the orbit. In this situation, if clinical signs persist and/or become aggravated over a 24 to 48-hour period of observation, surgical exploration is advisable. In our experience, involving four cases in which radiological evidence (including tomograms) was negative, exploration revealed a significant blowout fracture of the orbit in all of them.

\section{Treatment}

The literature of the past 20 years or so is replete with reports of the diagnosis and treatment of blowout fractures of the orbit.* The simplest and most benign surgical approach involves direct exposure of the floor of the orbit and replacement of the blown-out orbital floor with a piece of inert material which is fashioned to fit over the defect at the time of surgery. A variety of materials has been advocated to cover the orbital floor defect, including alloplastics (polyethylene, silicone, Supramid, cranioplast, teflon), tantalum mesh and cable, processed bovine bone, and so forth. Most of these materials appear to be well tolerated and serve as adequate substitutes for the orbital floor. A silicone rubber (silastic) implant less than I $\mathrm{mm}$. thick has been used in all our cases. The skin incision is made at the junction of the lower lid with the cheek skin. This incision allows an easy and quick exposure and generally avoids injuring the orbital septum. If the septum is inadvertently penetrated, it is important to repair the defect in order to avoid a baggy eyelid caused by herniation of periorbital fat. The orbicularis oculi muscle is separated in the line of its fibres to expose the orbital rim, and the periosteum is incised and elevated at the upper surface of the rim, enabling a wide sub-periosteal dissection in the orbit. This is necessary in order to demonstrate the herniated tissue. The fat and muscle can then be delivered from the maxillary antrum by gentle manipulation. One should be careful to separate the herniated tissues from the infraorbital nerve. Any loose bony fragments should be removed and a small hook is useful to deliver the bone. A silicone rubber implant (approximately I mm. or less in thickness) is shaped to fit over the defect and placed over the floor of the orbit. After it has been checked for proper fit in the subperiosteal position, it can be left in place without suturing or cementing. 
The blowout fracture is often located some distance behind the anterior rim of the orbit. It is therefore necessary to explore the orbital floor carefully since the fracture might be located in the posterior third. In one of our cases, the fracture was located more than $2 \mathrm{~cm}$. behind the anterior rim of the orbit and extended in a linear direction. Further exploration beyond the initial dissection revealed a fracture site containing a considerable amount of orbital material including muscle tissue.

The postoperative course is very benign and the silicone rubber implants are well tolerated. In over fifty cases of primary blowout fractures treated in this manner (this includes both the pure and impure blowout fracture) with a follow-up of 12 months to 3 years, the postoperative results have been excellent. All of the silicone rubber implants have remained in situ without evidence of infection. The elective scars are uniformly pleasing (Fig. 3, B and c) and no pseudoptosis or deepening of the supratarsal sulcus has occurred. Temporary exophthalmos was present in three cases but quickly cleared up. No enophthalmos or exophthalmos is now present in any case. The functional results have also been excellent. In the initial postoperative period a temporary hyperopia may be present but this disappears within I or 2 weeks. If the patient complains of diplopia during this time it can easily be treated with a frosted lens or a patch. In the initial postoperative period the maxillary antra frequently remain cloudy, but all postoperative $x$ rays have shown clear antra 6 to 8 months after surgery. Several patients had episodes of acute sinusitis but these were easily treated and cleared with medical management.

\section{Discussion}

The excellent results obtained with early diagnosis and treatment of blowout fractures o@ the orbit demonstrate the importance of carefully evaluating every patient who presents. with a "black eye". The presence of one or more of the characteristic signs of a blowout fracture should indicate the possibility that such a condition is present. A decision to explore the injury site should be based on clinical grounds which may or may not be supported by radiological evidence (although proper $x$ rays including the Waters view and tomograms will demonstrate most blowout fractures). If clinical signs are equivocal, it is best to defer a decision for 24 to 48 hours after which time the patient should be reevaluated. A definite increase in the vertical muscle imbalance warrants exploration. The surgical procedure is simple and benign and the prognosis is excellent.

However, all cases do not warrant exploration. Only those in which the initial or follow-up examination shows positive evidence of blowout fracture with diplopia, enophthalmos, etc., and a positive $x$-ray should be subjected to surgical exploration. Those patients who present with equivocal signs, that is, a minor degree of vertical muscle imbalance only or equivocal $x$-ray evidence or slight enophthalmos, should be followed at daily intervals. If one or more of the clinical signs increases in severity, then exploration as previously outlined seems to be indicated. Some of these cases will remain static for a day or so and then the patients begin to recover from their diplopia without requiring surgical intervention. It is not unreasonable to assume that such individuals might have suffered a small blowout in which there was little or no herniation of the muscles and only a minor degree of herniation of orbital fat.

\section{Bibliography}

I. ABrahams, I. W. (1966) Arch. Ophthal. (Chicago), 75, 510

2. AichmaIr, H. (1967) Klin. Med., 22, $5^{1} 7$

3. Aiello, L. M., and myers, e. N. (1965) Arch. Otolaryng., 82, 638. 
4. AUBry, M. (1965) Arch. Ophtal. (Paris), 25, 79

5. Bölcs, s. (1967) Szemészet, 104, 31 I

6. BRoWn, o. L., LONGAGRe, J. J., Destefano, G. A., WOOD, R. W., and KAHL, J. B. (1965) Radiology, 85, 907

7. Browning, c. w. (1967) Amer. F. Ophthal., 63, 955

8. - and WALKer, R. v. (1965) Ibid., 60, 684

9. COLE, H. G., and SMITH, B. (1963) Ibid., 55, 930

Io. CONVERSE, J. M. (1962) Plast. reconstr. Surg., 29, 408

I1. - and Sмrт, B. (1957) Brit. J. plast. Surg., 9, 265

12. - (1960a) Trans. Amer. Acad. Ophthal. Otolaryng., 64, 676

I3. - ( $1960 \mathrm{ob})$ In "Trans. int. Soc. plast. Surgeons, 2nd Congress, London, 1959", p. 28o. Livingstone, Edinburgh

14. - - (1961) 7. Florida med. Ass., 47, 1337

I5. - - OBEAR, M. F., and WOOD-SMITH, D. (1967) Plast. reconstr. Surg., 39, 20

16. CRAMER, L. M., TOOze, F. M., and Lerman, s. (1965) Brit. F. plast. Surg., 18, i 7 I

17. Cunningham, J. D., and marden, P. A. (1962) Arch. Ophthal. (Chicago), 68, 492

18. DOUbleday, L. C. (1962) Amer. med. Ass., 179, 27

19. FEORE, D. R. (1965) Clin. Radiol., 16, 347

20. FOLK, E. R. (1967) Ill. med. F., 131, 798, 829

21. FREEMAN, B. S. (1962) Plast. reconstr. Surg., 29, 587

22. FRIES, R. (1967) Klin. Med., 22, $5 \mathrm{I} 3$

23. FUeger, G. F., milauskas, A. T., and britton, w. (1966) Amer. F. Roentgenol., 97, 6I 4

24. Gahagan, L. o. (1962) Eye, Ear, Nose Thr. Monthly, 41, 915

25. Ginestet, G., and DUPUis, A. (1966) Gaz. méd. Fr., (1966) 73, 479

26. Goren, s. B., strauss, R. B., and osbon, D. B. (1966) Amer. J. Ophthal., 6r, 893

27. HARDY-SMITH, P. (1967) Aust. N.Z. J. Surg., 36, 319

28. JONES, D. E. P., and EVANS, J. N. G. (1967) F. Laryngol., 81, I 109

29. KAYE, B. L. (1966) Plast. reconstr. Surg., 37, 62

30. KROLl, M., and WOLPER, J. (1967) Amer. F. Ophthal., 64, I 169

31. LANG, W. (1889) Trans. ophthal. Soc. U.K., 9, 4I

32. LANGE, W. A. (1965) Plast. reconstr. Surg., 35, 26

33. Lerman, s., and CRAmer, L. M. (1964) Amer. F. Ophthal., 57, 264

34. Lewin, J. R., RHODes, D. H., JR., and PAVSEK, E. J. (1960) Amer. F. Roentgenol., 83, 628

35. LiPShUTZ, H., and ARdizone, R. A. (1965) J. Trauma, 5, 6 I 7

36. LLOYd, G. A. s. (1966) Brit. F. Radiol., 39, 933

37. LYLE, K. T. (1965) Arch. Soc. oftal. hisp.-amer., 25, 970

38. MCCLEVE, D. E., and Quickert, м. H. (1965) Arch. Otolaryng., 81, $4^{12}$

39. mGcoy, f. J., Ghandler, R. A., magnan, c. G., JR., MOORE, J. R., and siemsen, G. (1962) Plast. reconstr. Surg., 29, $38 \mathrm{I}$

40. meulemans, G. (1967) Ophthalmologica (Basel), 154, $46 \mathbf{r}$

41. milauskas, A. T., and fueger, G. F. (1966) Amer. F. Ophthal., 62, 670

42. Miller, G. R., and GLASer, J. S. (I966) Arch. Ophthal. (Chicago), 76,\$662

43. NASTEFF, D. (1967) Zbl. Chir., 92, 2207

44. NEELY, J. G. (1947) Brit. J. Ophthal., 31, 58I

45. Patterson, R. W., JR., mccoy, w. J., III, and Benedict, w. H. (1967) Arch. Ophthal. (Chicago), 78,360

46. Pelzer, R. H., and Garvin, w. J. (1958) Amer. F. Surg., 96, 735

47. PFEIFFer, R. L. (1943) Arch. Ophthal. (Chicago), 30, 718

48. PIAGET, F., Michelet, J., and GROS, J. C. (1967) J. franf. Oto-Rhino-Laryng., 16, 333

49. Pinkerton, R. M. H., ROSEN, D. A., DE MARgerie, J.-M., WYllie, A. K., and MEYer, J. W. (1967) Canad. F. Ophthal., 2, 103

5O. PROWLer, J. R. (1965) F. oral. Surg., 23, 5 
51. REeH, м. J., and tsujimura, J. к. (1966) Amer. J. Ophthal., 62, 79

52. rossberg, G. ( 1966) Klin. Mbl. Augenheilk., 149, 76 I

53. SChjelderup, H. ( I950) Acta ophthal. (Kbh.), 28, 377

54. Schmidt-hofmAnN-Friemel, E. (1967) Klin. Med., 22, 502

55. smith, J. P., and ausband, J. R. (i 965 ) N.C. med. J., 26, 494

56. smith, в., and converse, J. м. (1957) Trans. Amer. Acad. Ophthal. Otolaryng., 6r, 602

57. — and Regan, w. F., JR. (1957) Amer. 7. Ophthal., 44, 733

58. SOll, D. B., and POLEy, B. J. (I 965$)$ Ibid., 60, 269

59. Stephens, K. F., and reinecke, R. D. (1967) Trans. Amer. Acad. Ophthal. Otolaryng., 7x, 324

6o. vigario, G. D. (I966) Brit. J. Radiol., 39, 939

6I. (1967) Milit. Med., 132, 545

62. vinik, м., and gargano, F. P. (ig66) Amer. 7. Roentgenol., 97, 607

63. Woillez, M., tessier, P., Lekieffre, M., and dufour, D. (1967) Bull. Soc. franç. Ophtal., 80, 588

64. zizmor, J., smith, B., fasano, c., and converse, J. м. (1962) Trans. Amer. Acad. Ophthal., Otolaryng., 66, 802 